\title{
A Case of Takotsubo Cardiomyopathy after Surgery for Common Bile Duct Stones
}

\author{
Masayuki Tori Shigeyuki Ueshima Masaaki Nakahara
}

Department of Surgery, Osaka Police Hospital, Osaka, Japan

\section{Key Words}

Takotsubo cardiomyopathy · Hepato-pancreatic-biliary surgery · Elderly female

\begin{abstract}
Takotsubo cardiomyopathy (TC) is a rare reversible circulatory syndrome often detected in elderly patients after general surgery. We report the case of an 85-year-old woman who was admitted for obstructive jaundice and underwent ERCP and ENBD before operation. She finally underwent cholecystectomy and choledocholithotomy with the diagnosis of gallbladder and common bile duct stones. In the evening just after the operation, without symptoms of cardiac failure, her ECG suddenly exhibited abnormal ST-T elevation in leads II, III, and V2-V6, though neither CPK(MB) nor troponin T was elevated. Echocardiogram demonstrated basal hyperkinesis and apical dyskinesis, suggesting TC. Conservative treatment enabled recovery, ECG was normalized in a month, and the postoperative course was satisfactory. The stress on her during treatment might have been a cause of this unique cardiomyopathy, and it should be recalled that TC is a potential complication of hepato-biliary-pancreatic surgery.
\end{abstract}

\section{Introduction}

Ampulla cardiomyopathy, i.e. Takotsubo cardiomyopathy (TC), is a cardiac syndrome with acute onset defined by chest symptoms and elevated ST segment on the echocardiogram without significant narrowing of the coronary arteries. Early echocardiogram or left ventriculography of this syndrome reveals the shape of a 'Takotsubo', the name of a traditional Japanese octopus pot with a wide base and tapered top. Since TC mimics coronary artery disease, early diagnosis of it is very important. TC has recently been reported in similar cases after surgery. We report a case of TC after surgery for gallbladder and common bile duct stones. 


\section{Case Report}

An 85-year-old naturally nervous woman was admitted to the hospital for obstructive jaundice. She was not a smoker, had no past medical history including coronary heart diseases and no special family history. On admission, no abnormality was detected on ECG (electrocardiogram) (fig. 1a) or vital signs. ERCP (endoscopic retrograde cholangiopancreatography) and echography demonstrated gallstones and common bile duct stones (fig. 2). Laboratory data were as follows: WBC $21,600 / \mu \mathrm{l}$, platelets $95,000 / \mu \mathrm{l}$, T.Bil $7.9 \mathrm{mg} / \mathrm{dl}$, AST $98 \mathrm{U} / \mathrm{l}$, ALT $139 \mathrm{U} / \mathrm{l}$, CRP $16.8 \mathrm{mg} / \mathrm{dl}$, CEA $2.4 \mathrm{ng} / \mathrm{ml}$, and CA19-9 2 U/ml. Ultrasonography revealed many small gallbladder stones and ERCP revealed 4 stones (5-20 $\mathrm{mm}$ in size) in the common bile duct. EST (endoscopic sphincterotomy) was unsuccessful because those stones were large and stuck in the common bile duct.

Under a diagnosis of choledocolithiasis and cholecystitis with moderate icterus, the patient was first treated conservatively, with bile drainage by ENBD (endoscopic nasobiliary drainage) tube and administration of antibiotics. Though laboratory data showed sepsis (platelets $45,000 / \mu \mathrm{l}$ ) on the next day, she successfully recovered in 2 weeks (platelets 110,000/ $\mu$ l), when cholecystectomy and choledocholithotomy were successfully performed. Just after the operation, on the day of surgery, the ECG suddenly demonstrated ST-T elevation in leads II, III, and V2-6 (fig. 1b). Laboratory examination revealed slight elevation of CPK $(367 \mathrm{mg} / \mathrm{dl})$ and CPK-MB $(16 \mathrm{mg} / \mathrm{dl}, 4 \%)$ although troponin-I was normal and the echocardiogram showed asynergy with apical akinesis, basal hyperkinesis and decreased contraction of the heart (LVDd/Ds $=47 / 29 \mathrm{~mm})$ (fig. 3 ), and the heart resembled a 'Takotsubo'. Her CVP was constantly 7-9 $\mathrm{cm} \mathrm{H}_{2} \mathrm{O}$, and there were no symptoms of heart failure. Laboratory findings such as CPK-MB and troponin-I revealed no abnormality. Moreover, stress myocadial perfusion imaging demonstrated no abnormality at the same time. Therefore, she was diagnosed with TC. Echocardiogram and ECG were monitored carefully, but no medications were given. She recovered from sepsis in a week, and her pressure gradient was low, although no signs of cardiac failure were detected during the postoperative course. The C-tube was removed on the 4 th postoperative day. On day 2 after the operation, the ECG showed inverted T waves in leads V2-V5 (fig. 1c), and also leads V1V6 on day 22 (fig. 1d). Cardiac function improved in 2 weeks, and the postoperative course was uneventful.

\section{Discussion}

TC was first reported by Dote et al. [1] as a cardiac syndrome with acute onset, reversible ventricular wall motion disorder with chest symptoms, electrocardiographic changes with ST elevation and/or depression, and minimal myocardial enzymatic release mimicking acute coronary syndrome but without angiographical stenosis of the coronary arteries. Though most cases of TC have been reported in Japan, recently TC has come to be focused on in the US as well [2]. SPECT imaging has been reported as a method to assess TC [3], and TC might represent a stunned myocardium caused by disturbance of the coronary microcirculation.

Though the pathophysiological mechanism of TC remains unclear, some hypotheses have been offered for it. Owa et al. [4] reported that TC might be related to a disturbance of cardiac sympathetic innervation. On the other hand, Akashi et al. [5] insisted that catecholaminergic or adrenoceptor-hyperactive cardiomyopathy might be the cause of TC. Moreover, TC should be considered in aged patients and in postmenopausal females who must undergo physically and mentally stressful treatment [6].

It is generally thought that $\beta$-blockers might be effective for this syndrome, though they should be used carefully because of their various side effects [7]. It should be also reminded that like in the present case, no medication might be necessary with careful follow-up.

Recently, TC has been reported in connection with stress in surgery or anesthesia [8]. Besides the present case, only one case of TC [8] has been reported after hepatopancreatic-biliary surgery, although it might be suggested that similar cases are 
increasing. Since it is impossible to predict the occurrence of TC, ECG changes should always be monitored during and after surgery.

Useful criteria such as Mayo criteria [9] should always be borne in mind as early detection of TC is important. Our case was consistent with the Mayo criteria for the clinical diagnosis of TC.

In summary, we have described a case of postoperative TC mimicking an acute myocardial infarction. Circulatory status should always be monitored especially in aged and mentally stressed patients.

Fig. 1. Electrocardiogram. a Findings on admission (within normal limits). b Just after surgery (ST elevation in leads II, III, V2-V6). c Postoperative day 2 (negative T waves in leads V2-V5). d Postoperative day 22 (negative T waves in leads V1-V6).

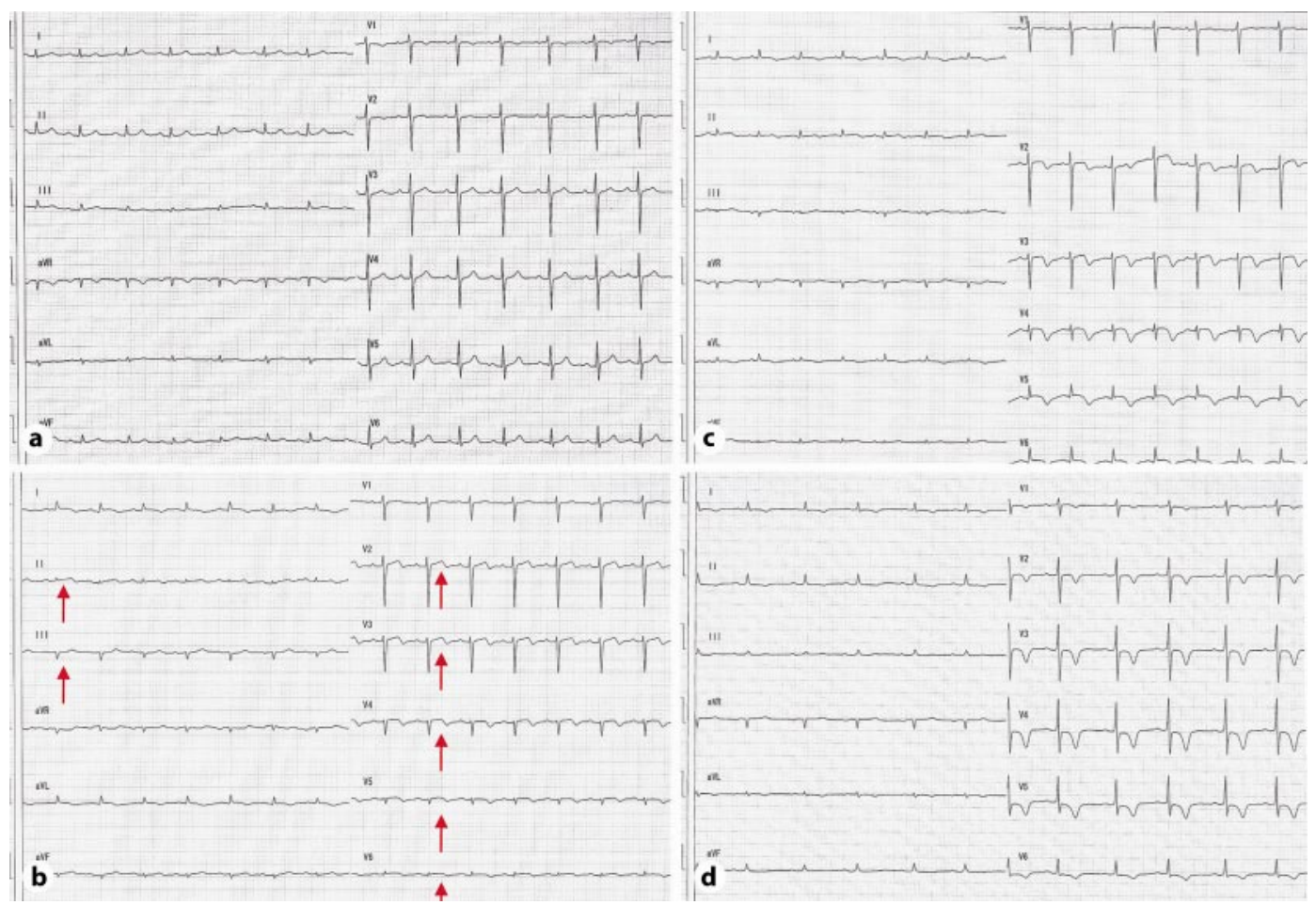


Fig. 2. Endoscopic retrograde cholangiopancreatography demonstrated at least 4 common bile duct stones and an ENBD tube was placed.

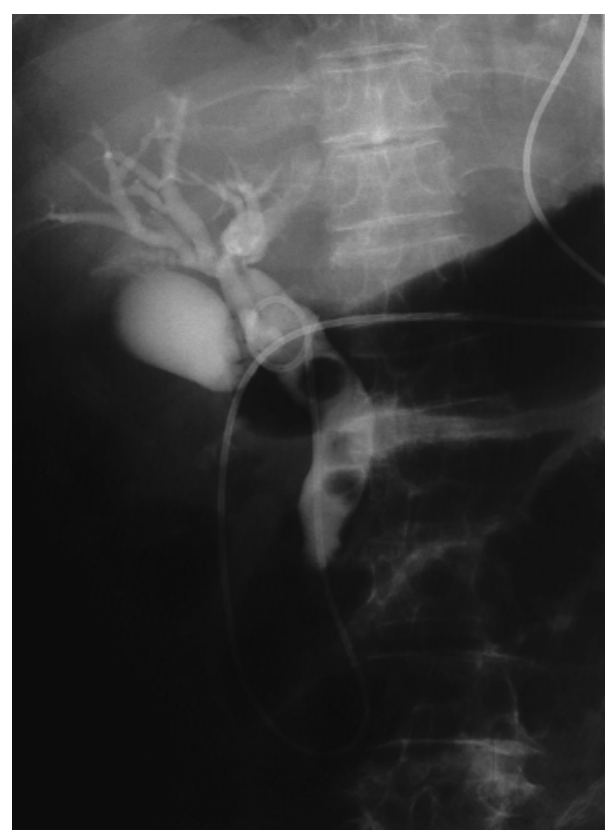

Fig. 3. Ultrasound cardiography demonstrates left ventricular apical akinesis with basal normokinesis $(\mathrm{LVDd} / \mathrm{Ds}=47 / 29 \mathrm{~mm})$. a Systole. $\mathbf{b}$ Diastole.
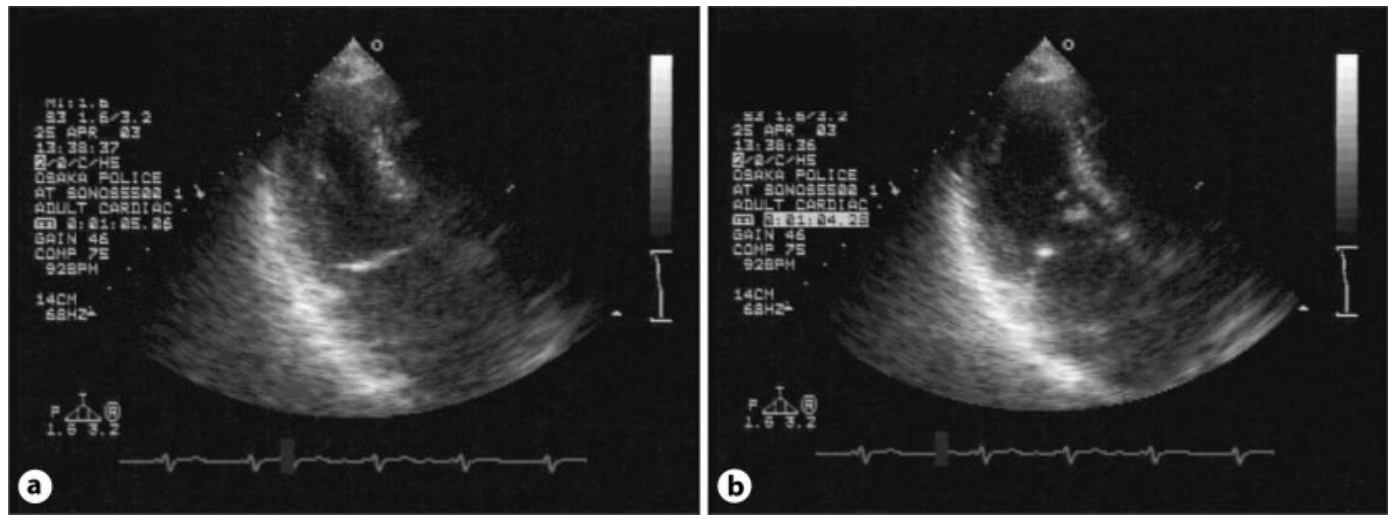


\section{References}

1 Dote K, Sato H, Tateishi H, Uchida T, Ishihara M, Yoshimura M: Myocardial stunning due to simultaneous multivessel coronary spasms: a review of 5 cases. J Cardiol 1991;21:203-214.

-2 Wachsman DE, Davidoff R: Takotsubo cardiomyopathy: A little-known cardiomyopathy makes its US debut. Cardiology 2004;102:119-121.

-3 Ito K, Sugihara H, Katoh S, Azuma A, Nakagawa M: Assessment of Takotsubo (ampulla) cardiomyopathy using ${ }^{99 \mathrm{~m}} \mathrm{Tc}$-tetrofosmin myocardial SPECT comparison with acute coronary syndrome. Ann Nucl Med 2003;17:115-122.

-4 Owa M, Arizawa K, Urasawa N, Ichinose H, Yamamoto K, Karasawa K, et al: Emotional stress-induced 'ampulla cardiomyopathy': discrepancy between the metabolic and sympathetic innervation imaging performed during the recovery course. Jpn Circ J 2001;65:349-352.

5 Akashi YJ, Nakazawa K, Sakakibara M, Miyake F, Koike H, Sasaka K: The clinical features of takotsubo cardiomyopathy. QJM 2003;96:563-573.

6 Gianni M, Dentali F, Grandi AM, Sumner G, Hiralal R, Lonn E: Apical ballooning syndrome or takotsubo cardiomyopathy: a systemic review. Eur Heart J 2006;27:1523-1529.

-7 Kyuma M, Tsuchihashi K, Shinshi Y, Hase M, Nakata T, Ooiwa H, et al: Effect of intravenous propranolol on left ventricular apical ballooning without coronary artery stenosis (ampulla cardiomyopathy): three cases. Circ J 2002;66:1181-1184.

8 Jensen JB, Malouf JF: Takotsubo cardiomyopathy following cholecystectomy: a poorly recognized cause of acute reversible left ventricular dysfunction. Int J Cardiol 2006;106:390-391.

-9 Bybee KA, Kara T, Prasad A, Lerman A, Barsness GW, Wright RS, et al: Systematic review: transient left ventricular apical ballooning: a syndrome that mimics ST-segment elevation myocardial infarction. Ann Intern Med 2004;141:858-865. 